\title{
O Coordenador Pedagógico no Contexto da Educação à Distância: Desafios e Possibilidades
}

\author{
The Pedagogical Coordinator in the Context of Distance Education: Challenges \\ and Possibilities
}

\author{
Hebert Rogério do Nascimento Coutinho ${ }^{1}$, Antonia Dalva França Carvalho ${ }^{2}$
}

\begin{abstract}
RESUMO
As mudanças educacionais e pedagógicas ocorridas ao longo das últimas décadas contribuíram para definir e consolidar as atribuições da função de coordenador pedagógico. Um dos fatores de maior influência nessas mudanças foram os avanços tecnológicos e suas implicações didático-pedagógicas. Neste contexto, a discussão aqui empreendida incide sobre os desafios trazidos pela tecnologia no que diz respeito à atuação do coordenador pedagógico frente as novas exigências pedagógicas resultantes da inovação tecnológica. A reflexão se ancora em uma pesquisa qualitativa de cunho bibliográfico, sendo as análises teóricas apoiada nas ideias de Alves (1998), Salvador (2000), Libâneo (2002) e Domingues (2014) para tratarmos sobre a função de coordenador pedagógico numa perspectiva diacrônica. Para compreendermos quais as implicações da mudança do perfil da sociedade pós-moderna na reformulação do entendimento das relações educacionais nas instituições de ensino nos fundamentamos no pensamento de Giddens (1991), Hall (2003) e Dias e Leite (2014). Por fim, tomamos por base as ideias de Gomez (2015) para entendermos quais implicações pedagógicas estão permeadas pelas inovações tecnológicas. Desse diálogo depreendemos que o percurso de consolidação da função de coordenador pedagógico sempre esteve imbuído de questão políticas, sociais, culturais e pedagógicas. Neste aspecto, tal consolidação é afetada diretamente pelo avanço tecnológico, exigindo, do coordenador pedagógico um entendimento sobre o novo perfil de cultura, seja ela escolar ou acadêmica, para (re)formular suas ações educativas.
\end{abstract}

Palavras-chave: Coordenador Pedagógico; Educação a Distância; Hibridismo Cultural.

\begin{abstract}
The educational and pedagogical changes that have taken place over the last few decades have contributed to defining and consolidating the attributions of the pedagogical coordinator function. One of the most influential factors in these changes were technological advances and their didactic-pedagogical implications. In this context, the discussion undertaken here focuses on the challenges brought by technology with regard to the role of the pedagogical coordinator in the face of new pedagogical requirements resulting from technological innovation. The reflection is based on a qualitative bibliographic research, with theoretical analyzes supported by the ideas of Alves (1998), Salvador (2000), Libâneo (2002) and Domingues (2014) to address the role of pedagogical coordinator in a diachronic perspective. In order to understand the implications of the change in the profile of postmodern society in the reformulation of the understanding of educational relations in educational institutions, we base ourselves on the thought of
\end{abstract}

${ }^{1}$ Doutorando do Curso de Pós-Graduação em Educação da Universidade Federal do Piauí PPGEd/UFPI, e-mail: hrn.coutinho@gmail.com

${ }^{2}$ Doutora em Educação. Professora do Programa de Pós-Graduação em Educação e do Centro de Ciências da Educação, do Campus Ministro Petrônio Portella, da Universidade Federal do Piauí - UFPI, adalvac@uol.com.br 
Giddens (1991) Hall (2003) and Dias and Leite (2014). Finally, we use the ideas of Gomez (2015) as a basis to understand which pedagogical implications are permeated by technological innovations. From this dialogue, we infer that the path of consolidating the role of pedagogical coordinator has always been imbued with political, social, cultural and pedagogical issues. In this aspect, such consolidation is directly affected by technological advances, requiring from the pedagogical coordinator an understanding of the new profile of culture, whether school or academic, to (re)formulate their educational actions.

Keywords: Pedagogical Coordinator; Distance Education; Cultural Hybridism.

\section{INTRODUÇÃO}

A figura do coordenador pedagógico, no Brasil, é, de maneira relativa, conhecida, mesmo sem um consenso geral sobre quais seriam suas atribuições. Nesse cenário, é pertinente ressaltar que, ainda, falta uma "unidade que sintetize os aspectos conceituais, estruturais e políticos da ação desse profissional [...]" (DOMINGUES, 2014, p. 15). Dessa forma, para que possamos entender de maneira mais profundas quais seriam essas atribuições, é necessário percebermos a importância do espaço escolar e suas implicações no desenvolvimento profissional docente.

Nesse entendimento, a figura do coordenador pedagógico ganha destaque por estar, tradicionalmente, vinculada ao papel de formador do docente no âmbito escolar, ou seja, esse profissional tem atribuições ligadas aos processos de organização de espaços coletivos de formação continuada nas escolas.

Dessa maneira, no percurso de consolidação das ações do coordenador pedagógico diversos desafios surgirão os quais estão ligados as tentativas de melhoria da qualidade da educação, tendo em vista que esse profissional se responsabiliza pela formação continuada da escola, favorece a articulação do projeto-político-pedagógico da escola, das reflexões coletivas, assim como, das situações ligadas ao acompanhamento das ações pedagógicas.

Assim, para a efetivação das argumentações, reflexões e críticas que serão aqui tecidas, tivemos como objeto de estudo o coordenador pedagógico e suas atribuições na Educação a Distância - EaD. Dessa forma, nos ativemos na discussão acerca da trajetória profissional do coordenador pedagógico de modo a relacionarmos suas atribuições com a cultura escolar e acadêmica que é praticada na educação a distância, percebendo quais as 
novas demandas trazidas por essa modalidade de educação e suas implicâncias pedagógicas.

Ademais, torna-se pertinente destacar a importância do espaço escolar e acadêmico para a consolidação das ações desenvolvidas pelo coordenador pedagógico, tendo em vista que nesses espaços se desenvolvem o currículo de formação do aluno, se manifestam os desafios de ensino e aprendizagem, são produzidos e mobilizados saberes e conhecimentos científicos e pedagógicos imbuídos pela prática, assim como, favorece a troca de experiências proporcionando a elaboração de saberes reflexivos relativos à ação docente.

Dessa forma, as reflexões sobre a atuação do coordenador pedagógico estão inseridas no contexto epistemológico do papel da escola e da universidade "como locus de desenvolvimento profissional e do docente, pela oportunidade de os professores refletirem coletivamente sobre seus saberes e saberes-fazeres" (DOMINGUES, p. 14, 2014), atribuindo, assim, aos coordenadores pedagógicos funções de articulação dos espaços coletivos de formação contínua do docente na escola e na universidade.

\section{COORDENAÇÃO PEDAGÓGICA E TRAJETÓRIA PROFISSIONAL: FORMAÇÃO (INICIAL E CONTÍNUA) E PERÍODO DE INICIAÇÃO}

Diante das mudanças ocorridas no início do século XXI as quais são decorrentes das construções empreendidas tanto em âmbito social, quanto institucional e tecnológico que se deram na segunda metade do século XX com advento da sociedade pós-moderna, vivemos períodos de transformações que abrangem todas as esferas sociais, atingindo, dessa forma, o fenômeno da Educação.

Nesse cenário de mudanças e transformações, o coordenador pedagógico é incitado a desenvolver novas competências, devido às novas exigências, modos de ser e outras demandas e perspectivas que estão vinculadas ao seu desempenho profissional nas escolas e universidades, fazendo com que este profissional "recaracterize" sua profissão, na intenção de firmar seu serviço de organizar o trabalho pedagógico, assim como de formação continuada do docente (DOMINGUES, 2014). 
Portanto, entender o trajeto percorrido pelo coordenador pedagógico, quais os aspectos legais permeiam esse trajeto, quais as implicações das mudanças ocorridas nesse percurso têm interferência direta nas ações pedagógica desse coordenador e quais as consequências na relação com EaD é de fundamental importância para que possamos construir um entendimento de todo esse contexto de transformação.

\subsection{A Coordenação Pedagógica e seu percurso}

Remontando os primórdios da coordenação pedagógica, Salvador (2000) localiza esse momento ainda no século XII, na Idade Média, momento este vinculado à história da inspeção escolar e da coordenação. Segundo a autora, o período da inspeção escolar pode ser divido em três momentos: confessional, de transição e técnico-pedagógico.

Inicialmente, tem-se uma grande influência da igreja no período confessional, mas que logo entra em declínio devido ao aumento das relações comerciais, fato este que propicia uma participação da sociedade civil nas relações educacionais, incentivadas pelos avanços científicos e filosóficos ao longo do século XIII. Em meados do século XVII surgem algumas escolas públicas em vários países da Europa, fazendo com que passem a coexistir escolas católicas e protestantes (SALVADOR, 2000).

Já o período técnico-científico acontece concomitante à Revolução Francesa no século XVIII, onde, através da Associação de Pais e Mestres (1793) os pais passam a ter o direito de interferirem na educação dos filhos, conforme afirma Salvador (2000). Assim, se inicia, no final do século XVIII, o caráter fiscalizador da supervisão, fato este que serve como referencial para entendermos os mecanismos de ordem estrutural de centralização e autoritarismo que perduram até hoje.

No caso brasileiro, devido ao seu caráter de colônia europeia, a educação ficou atrelada durante 210 anos à Companhia de Jesus, onde, os aspectos pedagógicos e administrativos tiveram suas bases fundadas de acordo com os preceitos dos jesuítas. Somente em 1759, momento este em que ocorreu a expulsão dos jesuítas, é que foi possível desarticular a estrutura educacional instaurada por estes, passando, assim, o domínio da educação pública para o Estado (DOMINGUES, 2014). A esse respeito, Salvador (2000) afirma, ainda, que somente com a vinda da Família Real Portuguesa no início do século XIX é que foram criadas escolas de nível técnico e superior para que 
fosse possível atender aos anseios da corte na intenção de capacitar o pessoal para assumir as novas funções administrativas que surgiram com a implantação do Império Ultramarino no território brasileiro.

A demora na implementação e expansão da estrutura escolar no Brasil está ligada, também, aos aspectos de densidade demográfica, fato este que só se torna favorável em meados do século XIX com a imigração italiana no atua estado de São Paulo. Uma das consequências dessa implementação escolar é a criação de Comissões de Ensino com funções fiscalizadoras que resulta na criação do cargo de Inspetor Escolar (1846), sendo este formado por uma comissão com a presença forte da igreja e representantes da sociedade (SALVADOR, 2000).

Já no período republicano, ocorre uma modificação no Conselho Superior com o surgimento do cargo de inspetor escolar. Em seguida, em 1897, há a extinção do Conselho Superior e a posterior criação da Inspetoria-geral, onde a direção e inspeção do ensino se deu através de um Inspetor Geral, auxiliado por dez Inspetores Escolares (SALVADOR, 2000).

No século XX, no ano de 1941, houve interferência política na inspeção por meio do Estatuto do Funcionário Público, o qual passou a exigir concurso e prova de títulos para o provimento do cargo de inspetor escolar, delegado de ensino e diretor de grupo escolar. Ademais, a Lei de Diretrizes e Bases (LDB) n 4024, de dezembro de 1961, Art. 65, estabeleceu que o inspetor deve ter sido aprovado em concurso, além de possuir conhecimentos pedagógicos e técnicos comprovados, seja na função de magistério, direção escolar ou no auxílio da administração escolar.

As transformações econômicas e políticas ocorridas durante a década de 1950 no Brasil, juntamente com a criação do Plano de Assistência Brasileiro-Americana no Ensino Elementar (PABAEE, 1957-1964) no Instituto de Educação de Belo Horizonte/MG, resultaram no surgimento da supervisão pedagógica como parte do que foi acordado para a elaboração deste plano.

Em seguida, com a criação da Lei de Diretrizes e Bases da Educação Nacional no 5.692/1971, o Art. 33 estabeleceu que o inspetor e o supervisor deverão possuir curso superior de graduação ou pós-graduação. No que diz respeito a reestruturação do curso de Pedagogia (1969), já há menção a habilitação em inspeção e supervisão. Dessa forma, 
a Lei 5.692/1971 e o Parecer 252/69 oficializaram a junção das atribuições do inspetor e do supervisor em uma única pessoa e função.

Já no decorrer da década de 1980, a função do coordenador pedagógico foi sendo atrelada às atribuições de assistente pedagógicos e dos orientadores educacionais, até culminar no surgimento do cargo de coordenador pedagógico em 1985, resultante da unificação dos cargos de assistente pedagógico e orientador educacional (DOMINGUES, 2014).

Ao analisarmos a literatura pertinente concernente à remontagem histórica do surgimento da função de coordenador pedagógico podemos constatar que sua demanda de trabalho está vinculada à formação do docente na escola, enfatizando a reflexão epistemológica da prática docente, na intenção de efetivar a aplicabilidade da teoria da didática produzida através das ações desenvolvidas no cotidiano escolar.

Portanto, ao pensarmos um espaço tão diversificado como o espaço escolar e acadêmico o qual é composto por uma gama de relações de natureza social, cultural política, econômica, familiar, religiosa e filosófica, podemos aqui afirmar que o espaço escolar e acadêmico nos proporciona percebê-los como uma rede de significados compartilhados. Para tanto, nos embasamos nas ideias de Pérez Gomez (2001) para afirmarmos que o campo cultural é constituído na produção de sentidos, sendo a escola e a academia locais de ampla produção cultural, tendo em vista que nesses espaços institucionais há uma inter-relação de culturas que, ao longo do tempo, resultaram na reconstrução das identidades e sentidos dos sujeitos pertencentes a esses espaços.

Nesse entendimento, passaremos agora para os desafios que se impõem ao coordenador pedagógico no século XXI como gestor dos processos de formação considerando as relações culturais, identitárias, políticas e educativas que se fazem presentes hodiernamente.

\subsection{A formação inicial do coordenador pedagógico e sua concepção pedagógica}

Partindo do contexto descrito anteriormente sobre o surgimento e consolidação da função de coordenador pedagógico constata-se que tal função é permeada por uma 
pluralidade de entendimentos sobre sua ação, bem como por uma intensidade no discurso sobre a formação contínua na escola e na academia.

Nessa perspectiva, é preferível que a formação inicial do coordenador pedagógico seja em um curso de Pedagogia, observando, ainda, o que preconiza a Lei no 9.394/96, juntamente com o Parecer CNE/CP 09/2001, a Resolução CNE/CP n. 01/2002 e o Parecer CNE/CP n.28/2004. Toda essa progressão legal culmina com o Parecer 05/2005 o qual é corroborado pela Resolução CNE/CP n. 01/2006.

Além disso, conforme estudos realizados por Domingues (2014) onde diversos coordenadores pedagógicos de escolas públicas do município de São Paulo foram entrevistados, foi possível identificar uma série de problemas vinculados a formação inicial desses coordenadores pedagógicos, provenientes da ineficácia na formação inicial devido à falta de preparo nessa formação para a execução das funções atribuídas aos coordenadores pedagógicos, dentre as quais podemos citar a ausência de embasamento legislativo, falta de conhecimento administrativo escolar, assim como a ausência de um preparo pedagógico para promover a formação docente.

Analisando a formação inicial dos coordenadores pedagógicos e o curso de Pedagogia, Libâneo (2002) nos possibilita analisar tal relação ao evidenciar a importância dos conhecimentos pedagógicos para a efetivação da

[...] formulação e acompanhamento da execução do projeto pedagógico-curricular, a orientação metodológica, a assistência pedogógico-didática aos professores na sala de aula numa relação interativa e compartilhada com os professores e alunos, colaboração nas práticas de reflexão e investigação, diagnóstico e atendimento das necessidades ligadas ao ensino e à aprendizagem dos alunos em conjunto com o professor, atividades de formação continuada, práticas de avaliação da aprendizagem. [...] (LIBÂNEO, 2002, p. 74).

Nessa perspectiva o coordenador pedagógico se torna um importante ator nas relações educacionais escolares e acadêmicas, situação este que requer uma formação inicial intrínseca à função para que, assim, seja possível aperfeiçoar e desenvolver sua profissionalidade com o intuito de atender às exigências dessa ação profissional, conforme preconiza Libâneo (2002).

Ademais, fazendo um paralelo com a pesquisa desenvolvida por Domingues (2014), ao analisarmos o contexto institucional de atuação dos coordenadores 
pedagógicos entrevistados, ficou evidente que a formação inicial desses profissionais não foi suficiente para atender as especificidades dessa atuação, incluindo as esferas conceituais e metodológicas.

Dessa forma, conforme Libâneo (1996), à Pedagogia Crítica pode contribuir para superar tal situação partindo de uma perspectiva coletiva, onde o trabalho do coordenador pedagógico deve ser guiado por uma aprendizagem significativa, onde a cultura passa a ser valorizada, assim como o conhecimento dos professores e alunos, na intenção de garantir intervenções pedagógicas que possibilitem condições democráticas, de justiça e igualdade para o grupo de trabalho.

Assim, fica evidente que a função do coordenador pedagógico é produto de uma formação inicial insuficiente, fruto de experiências educativas negativas, com a ausência de autonomia profissional e embasada em uma educação exercida pelas concepções de uma racionalidade técnica.

\section{EDUCAÇÃO À DISTÂNCIA E CULTURA ACADÊMICA: NOVAS PERSPECTIVAS PEDAGÓGICAS}

Ao analisarmos a trajetória profissional de surgimento e consolidação da função de coordenador pedagógico no Brasil, ficou perceptível que tal função está atrelada às ações de controle governamental das ações didático-pedagógicas inicialmente vinculada à igreja católica e, posteriormente, ao Estado. Além disso, as reflexões empreendidas sobre a formação inicial dos coordenadores pedagógicos nos permitiram constatar que os cursos de Pedagogia não abarcam a totalidade das ações que são atribuídas à esses profissionais, necessitando, assim, de uma reflexão crítica para que se possa perceber quais as limitações e soluções para superar essa problemática.

Desse modo, torna-se imperativo analisarmos quais as novas perspectivas pedagógicas que se mostram nesse momento de reformulação das ações institucionais escolares e acadêmicas, tendo em vista a grande demanda por uma educação pautada na virtualidade e suas implicâncias didáticas, pedagógicas e culturais e como essas demandas influenciam diretamente nas atribuições do coordenador pedagógico. 


\subsection{A Educação à Distância no Brasil e suas demandas didático-pedagógicas}

Considerando os dados contidos no Anuário Brasileiro Estatístico de Educação Aberta e a Distância (ABRAEAD, 2007), a Educação a Distância (EAD) no Brasil, entre os anos de 2004 a 2006, teve um incremento de 150\% na quantidade de alunos que praticam a modalidade EaD. Nessa perspectiva, conforme Dias e Leite (2014), no Brasil existe uma diversidade de políticas públicas direcionadas a EaD no intuito de estabelecer diligências pedagógicas nessa área, tais como a Universidade Aberta do Brasil (UAB), projeto este o qual é desenvolvido pela Secretaria de Educação a Distância (SEED).

Dessa forma, na intenção de evidenciarmos as consequências didáticopedagógicas oriundas do incremento da $\mathrm{EaD}$ no Brasil, considerando a relevância do acompanhamento, por parte dos profissionais da educação, das modificações aqui apontadas na $\mathrm{EaD}$ as quais ocorrem, também, na esfera administrativa, passaremos para um sucinto histórico do surgimento da EaD no Brasil.

De acordo com o que preconiza Alves (1998), mesmo considerando que a Educação a Distância teve início no século XV, na Alemanha, com Johannes Guttenberg, na realidade brasileira essa modalidade de educação iniciou no ano de 1904 a partir do estabelecimento das "Escolas Internacionais", sendo estas representantes das organizações norte-americanas. Contudo, o Jornal do Brasil já ofertava cursos profissionalizantes através de correspondência no ano de 1891, circunstância esta que põe em questão o momento no qual teve início a EaD no Brasil.

Na década de 1920 podemos citar o início da educação através do rádio a partir da fundação da Rádio Sociedade do Rio de Janeiro tendo a figura de Henrique Morize e Roquete Pinto os seus fundadores, sendo doada, no ano de 1936, ao Ministério da Educação e Saúde. No ano de 1937, foi criado o Serviço de Radiodifusão Educativa do Ministério da Educação. Já, em 1939 foi criado o Instituto Rádio Técnico Motor, na cidade de São Paulo. Posteriormente, no de 1941, o Instituto Universal Brasileiro foi concebido. Podemos citar, ainda, a Igreja Adventista que criou programas exibidos no rádio por meio da Escola Rádio-Postal, no intuito de ofertar cursos bíblicos por correspondência (ALVES, 1998).

Cabe ainda ressaltar que, no ano de 1946, o Serviço Nacional de Aprendizagem Comercial (SENAC) iniciou as atividades da Universidade do Ar. No ano de 1959 a 
Diocese de Natal/RN fundou escolas radiofônicas, se tornando, dessa forma, uma referência na $\mathrm{EaD}$ de cunho não formal do Brasil, por ter motivado o surgimento do Movimento de Educação de Base. Já no ano de 1973, o SENAC deu início aos cursos por correspondência, tendo como referência o modelo preconizado pela Universidade de Wisconsin - USA. (ALVES, 1998).

Considerando a fomentação da EaD no âmbito da educação pública, temos como referência o Instituto Brasileiro de Administração Municipal (IBAM) que iniciou suas atividades na EaD no ano de 1967, através do ensino por correspondência, registrando, dessa forma, o surgimento de novas entidades com foco na EaD no Brasil, ao longo das décadas de 1960 a 1980.

Ademais, na década de 1980 e início da década de 1990, considerando o surgimento de novas tecnologias, tais como as instruções programadas para microcomputadores, fitas K-7 e vídeos, ocorre um movimento de renovação da EaD no Brasil, bem como a efetivação do ensino de línguas estrangeiras (ALVES, 1998).

Todas as modificações acima descritas ocorridas desde o final do século XIX e, principalmente, no decorrer do século $\mathrm{XX}$, demonstram que os desafios atribuídos a EaD no Brasil demandam, ainda, de investimentos e formação para que toda a comunidade escolar e acadêmica possa aproveitar as potencialidades dessa modalidade de educação, assim como os gestores que são atores com relevantes atribuições na fomentação do processo educacional para que este se desenvolva de modo responsável e competente.

Dessa forma, considerando as reflexões empreendidas acima, fica evidente a necessidade de analisarmos os aspectos pedagógicos que se fazem pertinentes nessa perspectiva de reformulação educacional, considerando, ainda, as demandas pedagógicas e administrativas oriundas da $\mathrm{EaD}$ e suas implicações nas funções atribuídas ao coordenador pedagógico.

Assim, considerando a dimensão pedagógica da $\mathrm{EaD}$, fica perceptível a relevância de compreendermos a relação estabelecida entre educação, tecnologia e interação/interatividade. A esse respeito Levy (1993) nos estimula a refletir acerca do modelo tradicional de escola e suas consequências no modo de reprodução da interação estabelecida entre docentes e discentes balizadas nos procedimentos de falar/ditar do 
mestre. Essa perspectiva analítica do autor permite consideramos que o espaço virtual proporciona a execução de processos comunicativos diversificados da mídia clássica.

Nessa compreensão, considerando a distinção de categorias de dispositivos comunicacionais de Levy (1999), a categoria todos-todos é evidenciada no ciberespaço por consideramos que, nessa categoria de dispositivos comunicacionais, não existe diferenciação entre emissor e receptor, demandando, desse modo, uma nova forma de interação.

Dessa forma, a EaD possui um caráter inovador na sua perspectiva pedagógica, exatamente pelos novos espaços de aprendizagem criados pela virtualidade, demandando, assim, novos recursos didáticos, influenciando diretamente nos processos comunicativos entre docentes e discentes. Ademais, partindo da sistematização da relação entre o contexto tecnológico e o conhecimento evidenciado em diversos grupos sociais é possível afirmamos, pautados nas ideias de Lévy (1993), que a linguagem e a escrita estão presentes na história da humanidade através de uma forma eficiente de comunicação.

Entretanto, conforme preconiza Kenski (1997), os incrementos tecnológicos e digitais influenciaram diretamente nas modificações sofridas pela linguagem e a escrita no decorrer do processo de difusão global onde, tal difusão impacta, de forma direita, na saberes produzidos nos espaços institucionalizados.

Portanto, torna-se fundamental a compreensão dos desafios do coordenador pedagógico frente as mudanças pedagógicas oriundas do avanço tecnológico, assim como a compreensão das influências imbuídas nas mudanças acarretas pelas críticas empreendidas à sociedade moderna e como estas propiciaram o advento de novas concepções de cultura e, consequentemente, novas percepções acerca das relações educacionais nas instituições de ensino.

\section{DESAFIOS DO COORDENADOR PEDAGógiCo NA EDUCAÇÃo À DISTÂNCIA}

Diante das análises acerca das atribuições do coordenador pedagógico, a consolidação das suas atribuições e as implicações das mudanças trazidas pela sociedade pós-moderna em relação às concepções de identidade cultural, juntamente com o processo 
de globalização na modernidade tardia (HALL, 2003), é possível afirmarmos que a tecnologia demandou, das ações do coordenador pedagógico, uma nova percepção sobre as ações docentes e discentes, para conceber suas ações de formação e gestão das práticas pedagógicas nas instituições de ensino.

Dessa forma, entender quais as modificações contidas na cultura escolar e acadêmica resultantes das inovações tecnológicas para que o coordenador pedagógico possa acompanhar tais mudanças no âmbito cultural, educacional e pedagógico é de fundamental relevância para que possamos ter uma educação de qualidade. Assim, passaremos, a seguir, para as análises acerca da educação desenvolvida em ambiente virtual e suas implicações pedagógicas.

As mudanças advindas pela sociedade pós-moderna, as quais proporcionaram, não somente o descentramento do sujeito, mas, também, a reconstrução da ideia de cultura (GIDDENS, 1991; HALL, 2003), conforme preconiza Gomez (2015), tais mudanças tornaram possível a compreensão da pedagogia como ciência pública como base do ato de educar para a liberdade, para a esperança, para a autonomia e para a criticidade, de acordo com as ideias de Paulo Freire, tentando, atualmente, se reinventar diante da virtualidade.

Dessa forma, a autora nos direciona para uma percepção da relação estabelecida entre as dimensões socioculturais e os processos educativos atentando a possibilidade da reinvenção das práticas pedagógicas observando as novas territorialidades advindas da virtualidade, na intenção de concebermos uma educação "conectiva, rizomática, para a liberdade e em busca da solidariedade humana" (GOMEZ, 2015, p. 22).

Ademais, considerando a percepção atual da sociedade acerca da efetivação da noção de virtual, é possível afirmarmos que ainda há resistências para tal finalidade, tendo em vista que, no sentido comum, a palavra virtual ainda é compreendida como algo irreal, existindo somente como algo em potencial, porém, não possuindo caráter existencial concreto. Nessa compreensão, podemos afirmar, ainda, que o virtual não possui limitação temporal e espacial (LÉVY, 1999).

Assim, diante das reflexões acima empreendidas, torna-se possível afirmarmos que a dimensão virtual demanda uma reformulação na percepção identitária e ontológica do ser, considerando que a compreensão hodierna de relações sociais, educacionais, 
culturais, políticas e econômicas estão sendo reformuladas constantemente, devido a virtualidade.

Nessa compreensão, as mudanças tecnológicas e sociais acima descritas tem influência direta na Educação e, por conseguinte, nas práticas pedagógicas. Assim, balizados no que preconiza Gomez $(2004 ; 2015)$, podemos afirmar que as exigências oriundas da virtualidade, demandam uma prática educativa e pedagógica a qual a autora denomina de Pedagogia da Virtualidade que consiste numa pedagogia de caráter rizomático se distanciando de teorias e métodos deterministas, assumindo, assim, uma postura crítica diante da realidade social.

Desse modo, diante das reflexões aqui efetivadas, fica evidente que as consequências das práticas pedagógicas pautadas na virtualidade incidindo nas atribuições do coordenador pedagógico são, de modo objetivo, aspectos relevantes a serem considerando no planejamento e desenvolvimento das ações pedagógicas do coordenador pedagógico, considerando, ainda, a responsabilidade desse profissional no planejamento e fomentação da formação continuada dos docentes.

Portanto, considerar que o fenômeno virtual modificou as relações socioculturais e, consequentemente, proporcionou o surgimento de novas relações educacionais é admitir que tais modificações incidiram, também, na compreensão da cultura escolar e acadêmica. Dessa maneira, repensar as práticas pedagógicas dos coordenadores pedagógicos para que estes consigam atender à essas novas demandas é de fundamental importância para que consigamos atingir uma educação de qualidade.

\section{CONSIDERAÇÕES FINAIS}

Ao elencarmos o coordenador pedagógico e a educação a distância como objeto de estudo das análises aqui empreendidas tivemos como propósito desenvolver uma reflexão crítica acerca das demandas oriundas das inovações tecnológicas implementadas em meados do século XX e suas implicações nas relações educacionais desenvolvidas em âmbito institucional.

Para tanto, iniciamos com uma retomada, em uma perspectiva histórica, do surgimento e consolidação da função de coordenador pedagógico, assim como a formação 
inicial e continuada e seu período de iniciação profissional. A partir dessas análises foi possível constatar que a referida função esteve vinculada, inicialmente, às ações da Igreja, passando, em seguida, para o poder do Estado. Porém, nunca perdendo o seu caráter de inspeção e supervisão.

No que diz respeito a formação inicial do coordenador pedagógico, sua concepção pedagógica e o desempenho desse profissional na efetivação das suas atribuições, mesmo atualmente existindo um rigor na legislação competente quanto a formação adequada para assumir tal função, os relatos obtidos pelos autores utilizados como referência teórica aqui demonstrados, apontam para uma ausência de formação adequada para tal função. Isso evidencia um problema curricular, pois, não há disciplinas teóricas e práticas que consigam preparar os discentes para o desempenho da função de coordenador pedagógico de maneira apropriada.

Após as análises acerca do surgimento da educação a distância no Brasil e suas demandas didático-pedagógicas ficou evidente que tal surgimento sempre esteve vinculado ao avanço tecnológico disponibilizado. Este fato corrobora a nossa afirmação de que a cultura escolar e acadêmica vem sofrendo influência direta das modificações advindas do perfil de sociedade pós-moderna, situação esta que demandou da sociedade uma reformulação no entendimento das relações sociais e da concepção de "sujeito", assim como das relações culturais e educacionais. Assim, podemos afirmar, também, que o coordenador pedagógico deve acompanhar todas essas mudanças sociais e educacionais, considerando que as práticas pedagógicas são permeadas pelo fenômeno social e cultural.

Por fim, perceber que a cultura digital e a educação virtual está imbuída de uma educação que se caracteriza pela sua concepção híbrida de relações sociais, culturais e educacionais, só auxilia no fomento, planejamento e efetivação de uma educação de qualidade para que, assim, possamos formar sujeitos autônomos e críticos e, tudo isso, passa pelas atribuições da função de coordenador pedagógico.

\section{REFERÊNCIAS}

ALVES, J. R. M. Educação a Distância e as novas tecnologias de informação e aprendizagem. Artigo do programa Novas Tecnologias na Educação de 01 de fevereiro 
de 1998. Engenheiro 2001. Fundação Vanzolini, FINEP, Ministério da Ciência e Tecnologia. [Disponível em

http://www.clam.org.br/bibliotecadigital/uploads/publicacoes/186_1700_alvesjoaorober to.pdf - Acesso em 02/07/2020].

DIAS, R. A., LEITE, L.S. Educação a distância: da legislação ao pedagogo. 4. ed. Petrópolis, RJ: Vozes, 2014.

DOMINGUES, Isaneide. O Coordenador Pedagógico e a formação contínua do docente na escola. 1. ed. São Paulo: Cortez, 2014.

GIDDENS, A. As consequências da modernidade. Tradução: Raul Fiker. São Paulo: Editora UNESP, 1991.

GOMEZ, M. V. Educação em rede: uma visão emancipadora. São Paulo:

Cortez/Instituto Paulo Freire, 2004.

Pedagogia da Virtualidade: redes, cultura digital e educação. São Paulo:

Edição Loyola, 2015.

HALL, S. A identidade cultural na pós-modernidade. Tradução: Tomaz Tadeu da

Silva, Guaracira Lopes Louro - 8. ed. - Rio de Janeiro: DP\&A, 2003.

KENSKY. V. M. Novas tecnologias: o redimensionamento do espaço e do tempo e os impactos no trabalho docente. Caxambu: XX Reunião Anual da Anped, 1997.

LEVY, P. As tecnologias da inteligência: o futuro do pensamento na era da informática. Rio de Janeiro: Ed. 34. 1993.

Cibercultura. São Paulo: Ed. 34.1999.

LIBÂNEO, J. C. Que destino os educadores darão à pedagogia. IN: PIMENTA, S. G. (Org). Pedagogia: ciência da educação? São Paulo: Cortez, 1996.

Ainda as perguntas: o que é pedagogia, quem é o pedagogo, o que deve ser o curso de pedagogia. IN: PIMENTA, S. G. (Org). Pedagogia e pedagogos: caminhos e perspectivas. São Paulo: Cortez, 2002. P. 59-97.

PÉREZ GÓMES, A. I. A cultura escolar neoliberal. Porto Alegre: ArtMed, 2001.

SALVADOR, C. M. O coordenador pedagógico na ambiguidade interdisciplinar. Dissertação (Mestrado) - Programa de Pós-graduação em Educação, Pontifícia Universidade Católica, São Paulo, 2000.

Recebido em: 10/11/2021

Aprovado em: 05/12/2021

Publicado em: 10/12/2021 